\title{
DESAIN DAN SIMULASI MESIN SORTIR BIJI KOPI KERING DENGAN SISTEM PENGGERAK ENGKOL
}

\author{
Ahmad Fatih \\ Program Studi Teknik Mesin \\ Universitas Muria Kudus \\ Email: Ahmadfatih088@gmail.com \\ Masruki Kabib \\ Program Studi Teknik Mesin \\ Universitas Muria Kudus \\ Email: masruki.kabib@umk.ac.id \\ Akhmad Zidni Hudaya \\ Program Studi Teknik Mesin \\ Universitas Muria Kudus \\ Email: akhmad.zidni@umk.ac.id
}

\begin{abstract}
ABSTRAK
Biji kopi yang diolah oleh home industri masih banyak yang belum menggunakan mesin pengayak biji kopi. Produk biji kopi yang dihasilkan masih banyak ukuran yang belum memenuhi standar, sehingga daya jual biji kopi murah. Untuk mengatasi masalah tersebut dirancang mesin sortir biji kopi dengan skala home industri. Penelitian ini bertujuan mendesain dan mensimulasikan mesin sortir biji kopi agar dapat memisahkan ukuran biji kopi yang memenuhi standar SNI dengan kapasitas $300 \mathrm{~kg} / \mathrm{jam}$. Metode penelitian yang di gunakan adalah mendesain mesin dengan tahapan studi literatur, analisa kebutuhan sistem, desain mesin, perhitungan dan simulasi. Mesin sortir ini khusus digunakan untuk biji kopi jenis robusta. Hasil penelitian adalah desain mesin sortir dengan menggunakan 3 buah wadah alumunium yang disusun secara bertingkat. Setiap wadah memiliki lubang-lubang sortir dengan diameter yang berbeda yaitu $7 \mathrm{~mm}, 5 \mathrm{~mm}$, dan $3 \mathrm{~mm}$. Daya penggerak motor listrik 0,5 HP. Hasil simulasi nilai von-mises-stress frame adalah $623.4 \mathrm{Mpa}$, dan nilai displacement dengan beban $3 \mathrm{kN}$ mendapatkan hasil simulasi sebesar $0,5211 \mathrm{~mm}$.
\end{abstract}

Kata kunci: mesin sortir, biji kopi kering, kopi robusta

\section{ABSTRACT}

There are still many coffee beans processed by the home industry that do not yet use coffee bean sorting machines. There are still many coffee bean products that do not meet the standards, so the selling price of coffee beans is cheap. To solve this problem, a coffee bean sorting machine will be designed with a home industry scale. The objective of research is to design and simulate a coffee bean sorting machine in order to separate the size of coffee beans that meet SNI standards with a capacity of $300 \mathrm{~kg} /$ hour. The research method used is to design a machine with the stages of literature study, system requirements analysis, machine design, calculation and simulation. This sorting machine is specifically used for robusta coffee beans. The result of this research was a sorting machine design using 3 aluminum containers arranged in stages. Each container has sorting holes with different diameters of $7 \mathrm{~mm}, 5 \mathrm{~mm}$ and $3 \mathrm{~mm}$. The power 
of the electric motor is $0.5 \mathrm{HP}$. The simulation result of the von-mises-stress frame value is 623.4 $\mathrm{Mpa}$, and the displacement value with a load of $3 \mathrm{kN}$ gets a simulation result of $0.5211 \mathrm{~mm}$.

Keywords: Sorting machine, dry coffee beans, robusta coffee

\section{PENDAHULUAN}

Kopi merupakan komoditas perdagangan internasional terbesar kedua setelah minyak bumi, dan Indonesia adalah negara pengekspor kopi terbesar keempat setelah Brazil, Vietnam dan Kolombia. Namun, banyaknya petani kopi yang kurang akan pengetahuan bagaimana cara mengolah biji kopi yang baik dan benar akan berdampak terhadap turunnya kualitas kopi yang dihasilkan dan mengurangi kepercayaan konsumen terhadap produk kopi asli Indonesia.

Indonesia adalah pembuat salah satu dari lima negara produsen kopi terbesar di dunia. Tingkat produksi nasional kopi Indonesia cukup tinggi.Menurut Asosiasi Eksportir dan Industri Kopi Indonesia (2014)Indonesia memproduksi kopi sebanyak 660.000 ton serta melakukan eksport keluar negri sebanyak 414.000ton. Data yang dimiliki oleh Organisasi Kopi Internasional(2013) mengatakan bahwa konsumsi kopi domestik Indonesia mencapai 220 ribu ton [1].

Kebutuhan kopi berkualitas di indonesia semakin meningkat,dikarenakan hal itu di butuhkan teknologi yang semakin kompleks. Di dalam dunia industri di butuhkan mesin sortir Biji Kopi untuk memisahkan biji kopi berkualitas agar menaikkan harga jual biji kopi, bertolak dari mesin yang telah ada saat ini dalam industri kopi saat ini, masih menggunakan mesin sortir kopi yang belum di terapkan sistem kontrol. Maka dari itu adanya mesin biji sortir biji kopi yang menggunakan sistem kontrol akan sangat membantu.

Pengerjaan proses sortir kopi secara manual mempunyai beberapa kelemahan. Sebagai contoh tenaga operator sangat mudah terkuras, waktu pengerjaan cenderung lama dan produktifitas produksi rendah. Sedangkan pada mesin sortir kopi manual masih mempunyai beberapa kelemahan juga yakni masih menggunakan banyak tenaga dan kurang efisien. Hal ini terjadi karena pada proses pemisahan biji kopi kualitas 1, 2 dan 3 masih menggunakan tenaga manusia sehingga kurang efisien [1]. Hasil penelitian ini menyatakan bahwa perkembangan teknologi elektronik atau mikrokontroler sangat berpengaruh untuk menjadikan mesin sortir biji kopi menjadi otomatis

Pada mesin biji kopi parameter-parameter penting yang perlu diperhatikan adalah frekuensi getaran pengayak dan berat kopi yang harus ditanggung oleh pengayak. Kegagalan mesin penyortir bisa terjadi karena penentuan frekuensi getaran yang tidak tepat maupun beban berlebih yang harus ditanggung oleh pengayak. Frekuensi getaran pengayak dapat diatur dengan mengatur kecepatan motor penggerak mesin sortir. Sistem kontrol dibuat untuk mencegah terjadinya penumpukan biji kopi pada boks pengayak dan kecepatan putar motor dapat dikontrol dengan kecepatan yang telah ditentukan.

Pengembangan sistem sortir pada mesin pengayak pasir yang direncanakan untuk memenuhi kebutuhan pasir sebagai media penyimpan panas pada proses pembakaran di dalam boiler untuk meningkatkan efisiensi. Dengan mesin ini dapat dihasilkan pasir dengan ukuran $\leq 0.5$ mmdengan kapasitas pengayakan pasir 6,5 m3/jam [2]. Bagian-bagian utama mesin dimulai dari pemilihan motor penggerak, perencanaan kerangka, puli, poros, sabuk dan bantalan serta metode pemeliharaannya. Mesin ini digerakkan dengan daya $3 \mathrm{HP}$ dan putaran $1425 \mathrm{rpm}$, diteruskan ke puli penggerak yang berdiameter 3 inchi. Puli penggarak dihubungkan oleh $\mathrm{v}$ belt untuk menggerakkan puli yang berdiameter 10 inci. Sehingga putaran diturunkan menjadi $427 \mathrm{rpm}$. Puli memutar poros dengan diameter $30 \mathrm{~mm}$ yang dipasang bantalan eksentrik untuk menggetarkan ayakan pasir.. Peneliti lain yang melakukan pengembangan metode pengayak getar (vibrating screen) [3]. Pengayak getar 
ini memanfaatkan gaya-gaya eksitasi yang terjadi guna memisahkan material berdasarkan ukuran butir material yang dikehendaki agar mendapatkan hasil yang lebih maksimal.

Mesin pengayak biji kopi membutuhkan mekanisme getaran pada bagian pengayak biji kopi. Cara-cara untuk membangkitkan getaran pada mesin pengayak ada bermacam-macam. Salah satu cara yang dipakai pada pengayak biji ini menggunakan sistem massa tidak seimbang. Pada sistem ini poros engkol menghasilkan gerak getaran linear, selanjutnya getaran ini digunakan untuk menggerakkan ayakan. Sistem getaran yang mampu menahan beban yang sangat tinggi [3]. Metode sortir dengan poros engkol yang dapat digunakan untuk menghasilkan getaran [4].

Analisis dengan metode elemen hingga telah di lakukan terhadap frame untuk menopang beban, analisa ini menggunakan metode elemen hingga. Hasilnya menunjukkan tegangan yang paling terjadi pada daerah bearing dibawah pengayak [5].

Mekanisme gerakan mesin sortir biji kopi mempengaruhi produktifitas. Dengan memanfaatkan metode gerakan maju mundur dengan gerakan engkol (pengayakan) diharapkan biji kopi tersebut dapat terpisah dengan efisiensi yang tinggi [6].

Metode analisis tegangan telah dilakukan dengan menggunakan metode elemen hingga. Analisis tegangan di lakukan terhadap screw conveyor yang berfungsi mencampur garam dan iodium dapat menunjukkan analisa kegagalan tegangan von misses [7]. Analisis dengan metode elemen hingga hingga juga telah dilakukan pada frame mesin rol pipa. Analisis ini dapat menunjukkan besarnya defleksi pada frame [8].

Kelengkapan sistem kontrol pada mesin sortir kopi ini dapat menghilangkan penumpukan pada wadah sortir dan dapat mengatur kecepatan motor listrik secara stabil sehingga kegagalan pada proses sortir dapat dihindari.

Tujuan penelitian ini adalah untuk merancang dan menganalisa tegangan pada rangka mesin sortir biji kopi dengan kapasitas $300 \mathrm{~kg} / \mathrm{jam}$. Analisa tegangan menggunakan metode elemen hingga dan software autodesk inventor 2019. 


\section{METODOLOGI PENELITIAN}

Desain mesin sortir biji kopi yang dibuat meliputi bebrapa tahapan yang terlihat seperti pada Gambar 1. Secara garis besar tahapan dimulai dari studi literatur, membuat konsep desain, perancangan desain,perhitungan,dan simulasi.

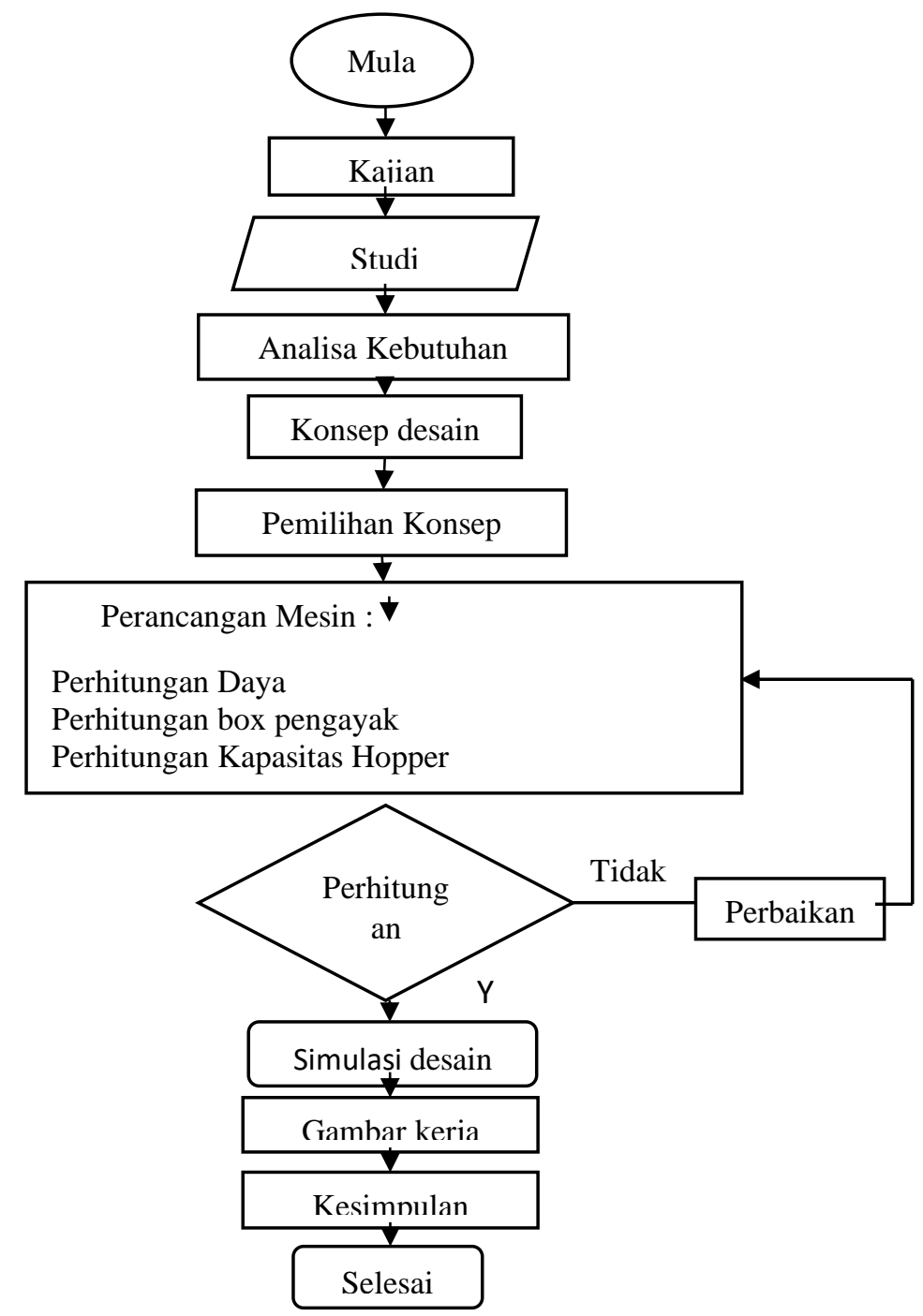

Gambar 1. Diagram alir desain mesin sortir biji kopi

1. Studi Literatur.

Studi literatur meliputi : pencarian berupa jurnal dan skripsi-skripsi yang sudah pernah dibuat dan terkait dengan desain sortir biji kopi.

2. Analisa Kebutuhan.

Analisa kebutuhan : menyesuaikan kebutuhan dalam aspek teknik, aspek manufaktur, aspek perakitan, aspek perawatan, aspek ergonomi, aspek lingkungan dan aspek ergonomi agar memudahkan pengguna alat tersebut. 
3. Konsep Desain.

Melakukan proses konsep desain dengan memberikan gambaran perbandingan dari alat yang di bangun dengan suatu pengartian mesin sortir biji kopi.

4. Pemilihan konsep desain.

Melakukan proses pemilihan konsep desain dari beberapa konsep desain yang telah di sajikan, dengan mempertimbangkan segi keefektifitas sistem kerjannya.

5. Perancangan.

Menentukan dimensi rangka sebagai salah satu perhitungan mesin.

6. Perhitungan dan simulasi.

Melakukan perhitungan rangka secara manual dan menganalisa dengan menggunakan metode elemen hingga sebagai pembanding perhitungan manual dan simulasi.

\section{HASIL DAN PEMBAHASAN}

\subsection{Desain Mesin}

Pemilihan desain ini dilakukan melalui beberapa tahapan variabel-variabel tertentu dan pertimbangan dari beberapa konsep desain, maka dari hasil pertimbangan tersebut berhasil terpilih konsep desain Mesin sortir biji kopi seperti gambar 2 .

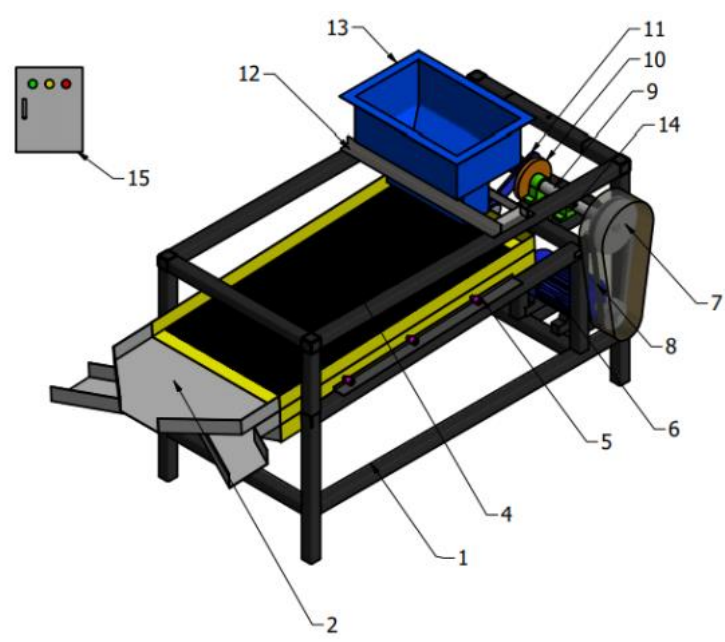

Gambar 2. Desain Mesin sortir biji kopi dengan system gerak engkol.

Pada Gambar 2. terlihat bahwa mesin sortir biji kopi konsumsi terdiri dari komponen : 1)Rangka, 2) Pengayak, 3) Corong keluar, 4) Bantalan, 5) Motor 6) $V$ belt, 7) Penutup Pulley, 8) Pulley, 9)Poros, 10)Bearing, 11) Engkol, 12) Batang engkol, 13)Hopper, 14)Pengunci hopper.

Prinsip kerja sortir biji kopi : Tenaga dari motor di teruskan ke poros sentrik melalu pully yang di pasang menjadi satu di poros bertujuan memaksimalkan drorongan pada pengayak,dan corong ikut bergerak pada saat mesin dijalankan yang bertujuan dapat mendorong biji kopi keluar lebih maksimal.

\subsection{Fungsi komponen}

1) Hopper ini berfungsi sebagai tempat masukan dan menampung kopi.

2) Pengunci Hopper berfungsi untuk mengunci hopper waktu mesin sedang bekerja agar tidak berubah posisi.

3) Pully ini berfungsi sebagai penghantar daya. 
4) Sabuk V-Belt mesin penggiling ini berfungsi meneruskan putaran pully poros penggiling yang terhubung dengan motor.

5) Motor penggerak mesin sortir ini berfungsi menggerakkan tranmisi sabuk/ pully untuk memutar poros penggiling dan memutar exciter.

6) Box pengayak berfungsi sebagai tempat proses pengayakan.

7) Pully V-Belt dan poros vibrating exciter ini berfungsi meneruskan putaran poros pully yang terhubung dengan motor, Vibrating Exciter berfungsi sebagai penghasil gerakan engkol pada pengayak.

8) Rangka berfungsi mendukung penopang komponen mesin dan meredam getaran getaran dari komponen mesin.

9) Output berfungsi sebagai keluaran dari outflow kopi terdiri dari tiga bagian yaitu duang keluaran dengan ukuran yang berbeda.

10) Engkol berfungsi untuk menggerakkan atau mendorong pengayak dengan kecepatan yang telah di tentukan.

\subsection{Perhitungan Mesin}

a. Daya merupakan besar usaha atau energi tiap satu satuan luas waktu, dihitung dengan persamaan 1 .

$$
P=\frac{w}{t}
$$

Dimana P adalah Daya (watt), w adalah Usaha (joule), t adalah waktu (second).

Daya juga dapat dihitung dengan persamaan 2.

$$
\mathbf{P}=\frac{2 \pi \cdot n \cdot T}{4500}
$$

Dimana n adalah Putaran poros (rpm), T adalah Torsi (kg.m), P adalah Daya (HP), $\mathrm{T}$ adalah $\mathrm{F}$ x r, $\mathrm{r}$ adalah Jarak sumbu poros

b. Perhitungan poros

Torsi yang terjadi pada poros, dihitung dengan persamaan 3 .

$$
\mathrm{T}=\left(\mathrm{T}_{1}-\mathrm{T}_{2}\right) . \mathrm{R}=T=\frac{P .60}{2 \pi \cdot N}
$$

Dimana $\mathrm{T}$ adalah Torsi pada poros (Nm), T1 adalah gaya tegangan pada sisi kencang sabuk (kg), T2 adalah gaya tegangan pada sisi kencang sabuk $(\mathrm{kg}), \mathrm{R}$ adalah radius pully (mm), $\mathrm{P}$ adalah daya (watt), $\mathrm{N}$ adalah putaran poros (rpm)

Momen bending yang terjadi pada poros, dihitung dengan persamaan 4 .

$$
\mathbf{M}=\mathbf{F} . \mathbf{L}
$$

Dimana M adalah momen bending $(\mathrm{kg} / \mathrm{mm}), \mathrm{F}$ adalah gaya yang terjadi $(\mathrm{kg}), \mathrm{L}$ adalah panjang atau jarak terhadap gaya $(\mathrm{mm})$ 
c. Momen equivalen, dihitung dengan persamaan 5.

$$
\mathrm{Te}=\sqrt{M^{2}+T^{2}}
$$

Dimana Te adalah Momen equivalen $(\mathrm{kg} / \mathrm{mm}), \mathrm{M}$ adalah momen bending atau lentur $(\mathrm{kg} / \mathrm{mm}), \mathrm{T}$ adalah torsi atau momen punter $(\mathrm{kg} / \mathrm{mm})$

d. Perhitungan diameter poros, dihitung dengan persamaan 6 .

$$
\begin{gathered}
T e=\frac{\pi}{16} \cdot F s \cdot D^{3} \\
d^{3}=\frac{16 \cdot T e}{\pi \cdot F s}
\end{gathered}
$$

Dimana d adalah diameter poros, Fs adalah Tegangan geser $\left(\mathrm{kg} / \mathrm{mm}^{2}\right)$

e. Perhtiungan engkol, dihitung dengan persamaan 7 .

$$
V=\frac{2 L N}{60}=\frac{L N}{30}
$$

Dimana V adalah Kecepatan Engkol, L adalah Langkah (m), N adalah Putaran Mesin (Rpm)

f. Frame Mesin, dihitung dengan persamaan 8 .

$$
\sigma \text { izin }=M / E
$$

Dimana $\sigma$ izin adalah Tegangan Izin Suatu Bahan (N/mm), M adalah Momen Lentur (N/mm), E adalah Modulus elastisitas (mm)

g. Momen Inersia, dihitung dengan persamaan 9. Dengan penampang kerangka utama di tunjukka pada gambar 3.

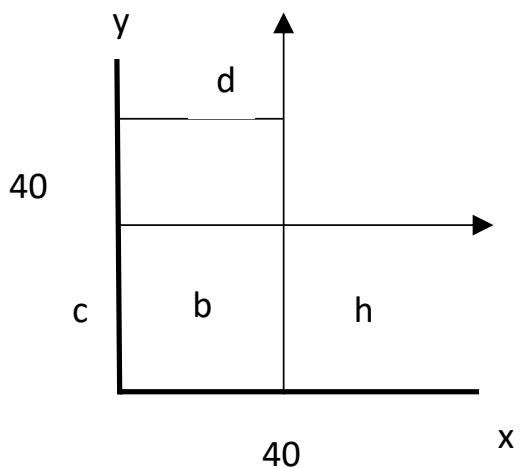

Gambar 3. Penampang rangka utama

$$
I=I_{X^{\prime}}=\frac{1}{12} b h^{3}-\frac{1}{12} b^{\prime} h^{\prime 3}
$$


h. Tegangan Permukaan dihitung dengan persamaan 10.

$$
\sigma=\frac{M \cdot C}{I}
$$
frame

Dimana $\mathrm{M}$ adalah Momen , $\mathrm{C}$ adalahTitik tengah y , I adalah Momen inersia pada

i. Tegangan Von mises, dihitung dengan persamaan 11.

$$
\text { safety factor }=\frac{\text { Yield Point Stress }}{\text { Working atau design stress }}
$$

Hasil perhitungan desain mesin menghasilkan nilai seperti pada tabel 1 .

Tabel 1. Hasil dari perhitungan mesin sortir biji kopi

\begin{tabular}{ll}
\hline Perhitungan & Hasil \\
\hline Torsi yang terjadi & $229,58 \mathrm{~kg} / \mathrm{mm}$ \\
\hline Daya mesin & $334,23 \mathrm{Watt}$ \\
\hline Tegangan geser izin & $2,66667 \mathrm{~kg} / \mathrm{mm}$ \\
\hline Diameter poros & $25,4 \mathrm{~mm}$ \\
\hline
\end{tabular}

Pada perhitungan Frame menghasilkan nilai seperti pada tabel 2.

Tabel 2. Hasil dari perhitungan Frame sortir biji kopi

\begin{tabular}{ll}
\hline Perhitungan & Hasil \\
\hline Titik berat & $600 \mathrm{~mm}, 40 \mathrm{~mm}$ \\
\hline Momen Inersia & $109332,6 \mathrm{~mm}$ \\
\hline Momen Gaya & $465000 \mathrm{~N} / \mathrm{mm}$ \\
\hline Tegangan Permukaan & $17,02 \mathrm{~N} / \mathrm{mm}^{2}$ \\
\hline Tegangan geser & $0,0125 \mathrm{~N}$ \\
\hline Tegangan von mises & $617 \mathrm{Mpa}$ \\
\hline
\end{tabular}

3.4. Analisa Tegangan Frame

3.4.1 Besar tegangan von mises pada rangka/frame

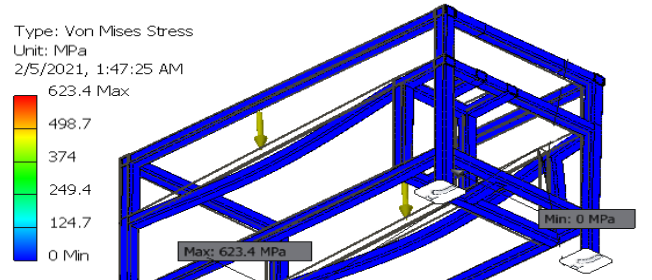


Gambar 4. Analisa Von mises stress pada rangka mesin sortir biji kopi

Pada gambar 4. Menunjukan distribusi tegangan ke seluruh bagian geometri mesin sortir biji kopi mempunyai nilai von mesis stress sebesar $623.4 \mathrm{Mpa}$ dan nilai von mises stress minimal $0 \mathrm{Mpa}$.

Dari hasil perhitungan teoritis di dapatkan nilai von mises 617,7 Mpa sedangkan dengan metode simulasi tegangan von mises yang dihasilkan sebesar 623,4 Mpa. Terdapat selisih sebesar $0,9 \%$, sehingga dapat dinyatakan hasil perhitungan tegangan von misses memenuhi syarat.

\subsubsection{Nilai Displacement pada mesin sortir biji kopi}

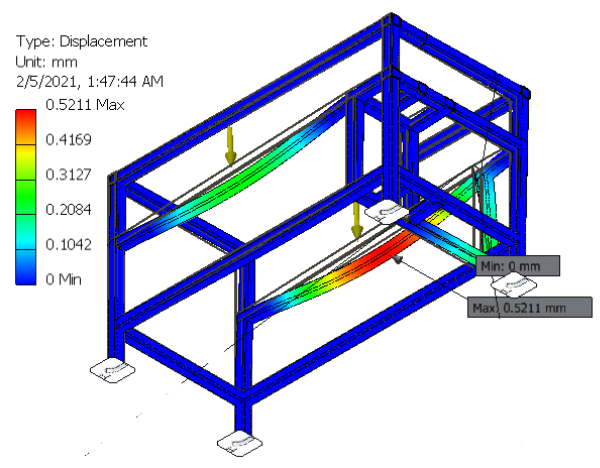

Gambar 6. Displacement pada rangka mesin sortir biji kopi.

Pada gambar 6 menunjukan distribusi tegangan ke seluruh bagian geometri rangka mesin sortir biji kopi mempunyai nilai Displacement maximal sebesar 0,5211 $\mathrm{mm}$ dan nilai Displacement minimal sebesar $0 \mathrm{~mm}$.

Pada perhitungan teori nilai Displacement maximal sebesar $0,125 \mathrm{~mm}$, sedangkan pada metode simulasi nilai Displacement maximal sebesar 0,521 mm. Mempunyai perbedaan sekitar $13 \%$

Berdasarkan hasil penelitian terhadap rancangan mesin sortir biji kopi mempunyai daya 334,23 Watt atau motorl listrik penggerak $0,5 \mathrm{HP}$ dan torsi yang terjadi $229,58 \mathrm{Kg} / \mathrm{mm}$ yang mempunyai tegangan geser izin sebesar 2,66667 Kg/ $\mathrm{mm}^{2}$ mesin ini menggunakan poros berdiameter 25,4 (1 inch) yang sesuai dengan bantalan 6006 yang digunakan, dengan menggunakan metode lemen hingga dalam merancang desain dan mensimulasikan mesin sortir biji kopi. 


\section{KESIMPULAN}

Dari hasil perhitungan perancangan dari frame mesin sortir biji kopi dapat di simpulkan mesin sortir biji kopi dengan dimensi ukuran 1250 x 600 membutuhkan daya motor listrik penggerak $0,5 \mathrm{HP}$, mendapatkan hasil simulasi nilai von-mises-stress frame adalah $623.4 \mathrm{Mpa}$, dan nilai displacement dengan beban $3 \mathrm{kN}$ mendapatkan hasil simulasi nilai sebesar $0,5211 \mathrm{~mm}$.

\section{DAFTAR PUSTAKA}

[1] R. Loice and N. Chrisman Santoso, 2015, "Perancangan Alat Bantu Sortir Biji Kopi Peaberry," research report engineering science, volume 2.

[2] E. W. B. Siahaan, "Perancangan Mesin Pengayak Pasir Dengan Kapasitas 6 , 5 m3/jam," J. Darma Agung, vol. XXVI, no. 1, pp. 460-475, 2018.

[3] Selamet. M. Kabib, R. Winarso, A. Zidni Hudaya, 2020. Manufaktur Mesin Penggiling Dan Pengayak Garam Konsumsi. Jurnal Crankshaft, Vol. 3, No. 1, Hal. 55-63.

[4] Fanni, Fattah. 2016,"Rancang bangun mesin pengayak pasir otomatis ", Teknik Mesin Universitas Muhammadiyah Tangerang Email : vanfattah@gmail.com, 2016.

[5] Hamdani Ahmad. Qomaruddin Qomaruddin. R. Winarso, M. Kabib. 2020. Perancangan Dan Simulasi Tegangan Rangka Mesin Pres Batako. Jurnal Crankshaft, Vol. 3, No. 2, Hal. 1-6.

[6] Zulfikar. Indra, Mawardi and Mawardi . 201 9. Pembuatan Mesin Sortir Biji Kopi Menggunakan Mekanisme Getar dengan Gaya 1 Hp. Jurnal Mesin Sains Terapan, Vol. 3, No. 1, Hal. 28-30.

[7] A. Rofeg, M. Kabib, 2018 "Analisa Tegangan Screw Conveyor Pada Mesin Pencampur Garam Dan Iodium Sesuai SNI 3556 Dengan Metode Elemen Hingga," Jurnal Simetris . Teknik Mesin, Elektro dan Ilmu Komputer., vol. 9, no. 2, pp. 935940, doi: 10.24176/simet.v9i2.2452.

[8] S. Kuntoro, M. Kabib, 2018, Analisis Kekuatan Dies Frame Link Pada Mesin Roll Pipa 2 In Penggerak Hidrolik Dengan Metode Elemen Hingga, Jurnal Simetris, Volume 9, Nomor 2, pp. 941 - 946. 